\title{
Research on the Selection of Knowledge Cooperative Partners in the Technology Alliance Based on Imperfect Information Dynamic Game Theory
}

\author{
Chunhua Hu \\ School of Management of Wuhan Donghu University, Hubei Province, China \\ 600690@163.com
}

\begin{abstract}
Exploration and research on technology alliance partner selection based on imperfect information dynamic game is the premise and guarantee to further promote the knowledge collaboration efficiency of Enterprise, University and Research Institute, to promote the sustainable development of technology alliance. This paper analyzes the connotation of knowledge cooperative partners in the technology alliance, discusses the partner selection of Technology Alliance Cooperative game process on the basis of imperfect information dynamic game theory, and studies the effective screening process for partner selection of knowledge cooperative partners in the technology alliance. This research shows that the performance improvement and cooperation and competition are the two major problems facing by collaborative innovation partner of technology alliance. Knowledge sharing, mutual compatibility, subjective ability and commitment are the key elements of partner selection, reasonable selection of partners can continue to improve innovation ability of collaborative technology alliance.
\end{abstract}

Keywords: Technology Alliance; Knowledge collaboration; Dynamic game; Imperfect information; partner selection

\section{Introduction}

Technology alliance is an important part of the national innovation system and effective cooperation organization, this form can help enterprises, universities and institutes enhance interaction and cooperation, realize the complementary advantages of resources and competitiveness, promote technological innovation efficiency, promote technological innovation and constantly emerge into reality benefits, so as to improve the competitive advantages of all parties [1]. From the perspective of knowledge management, cooperative innovation process in technology alliance is actually the process of knowledge innovation, also is the process of knowledge acquisition, knowledge appliaction and finally realize the knowledge collaboration, even form the main body of knowledge advantages [2]. It is in the process of collaborative innovation of technology alliance, knowledge flow has become one of the key factors, in the current knowledge collaboration has gradually become a hot issue, quickly becomes a new research direction of knowledge management theory[3,4]. From the characteristics of knowledge collaboration, including some kind of activities, such as collaborative research, collaborative cooperation, collaborative production, collaborative marketing, collaborative procurement, collaborative commerce, a variety of cooperative subjects innovate and cooperate in the process of collaboration. According to the range of activities, knowledge collaboration is divided into individual, group, organization and inter organization collaboration [5].

For enterprises, universities, research institutes, innovation has become the soul of the competitiveness. Facing to solve the innovation problem in complex system, chaotic system, whether between organizations or in organization, it can make innovation work more efficient and easier to success. As a result, the knowledge collaboration in technology alliance is a process of knowledge flow, which several knowledge resources subjects to participate in. It is a strategic cooperation mode and organizational innovation mode for the effective integration of knowledge resources. The knowledge acquisition and knowledge application for subjects in technology alliance promote the formation of knowledge collaboration relations, realize the knowledge cooperative effect for overall interests greater than the individual's. In this process, collaborative partner selection is the key. 


\section{The Game Process of Knowledge Collaboration Partner Selection in Technology Alliance}

Knowledge collaboration in Technology alliance achieve the sharing of knowledge resources and complementary advantages through the internalization of external knowledge resources, is useful in helping organizations to shorten the time of innovation, and enhance the competitive position of the organization.

The selection of knowledge collaboration partner is the most basic and the most important part in the process of knowledge collaboration in technology alliance. It is clear that whether the partner selection is correct closely related to the success or failure of knowledge collaboration. From the current literature, the research of partner selection is mainly carried out from the selection method. However, the research on the partner selection in the process of knowledge collaboration is not so much, which is related to the characteristics of the current technology alliance. The partner selection in current technology alliance is not paid much attention with a government background. In fact, the selection of knowledge partner in technology alliance is directly related to the realization of efficiency in technology alliance. This part mainly studies how to solve the partner selection problem especially high quality partner selection in technology alliance. The solution of this problem is also one of the key issues in the knowledge collaboration of technology alliance.

Therefore, for the organization with high level knowledge endowment, because of its strong ability to absorb knowledge, can gain more benefit from knowledge collaboration, so its they are willing to knowledge collaboration, the partners also can obtain value-added knowledge from the organization, so they are willing to choose the high level knowledge endowment organization as collaborative object. We can see, only in the premise of the interests for the two sides are likely to choose knowledge collaboration. And mechanism for knowledge collaboration partner selection is the key influence factors for knowledge collaboration partner selection, through the strict partner mechanism can improve the knowledge value-added for knowledge collaboration in technology alliance, meanwhile through the protection of intellectual property rights to reduce risk and cost. We can achieve a reasonable partner selection results from the effective control of the knowledge collaborative partner selection mechanism, reduce negative utility risk of the adverse selection of partner selection.

\section{Effective Selection of Knowledge Collaboration Partner in Technology Alliance}

According to the above analysis, in order to help the organization choose partners correctly in the knowledge coordination in technology alliance, to reduce the negative effect, to improve cooperation efficiency, a scientific partner selection mechanism should be established. In the choice of partners, must consider the both sides from technology, operational advantages and disadvantages and the new situation after the success of cooperation. Technology alliance innovation, although have advantages of mutual benefit sharing, but if you do not deal with the cooperation relationship between each other, also may cause loss of interest, for example disputes in intellectual property rights.

The main idea of partner screening model is: firstly, set a standard to filter partners fastly, will decline in the number of potential partners to the appropriate range, to reduce the workload of the late period; at the same time, make a comprehensive assessment of partners in a higher standard, remove away the candidate partners with lower efficiency; finally, to optimize the subjects participating in knowledge collaboration in technology alliance to select partner combination.

Partner selection run through the whole process of knowledge collaboration in technology alliance, it not only includes the selection of collaborative partners of knowledge collaboration in the technology alliance at the beginning, but also include the dynamic adjustment of partner's selection in the process of knowledge collaboration of technology alliance. In practical application, the evaluation index system and selection evaluation model of partner selection should be adjusted according to the specific task and influencing factors of partner selection.

In the screen of partner selection, the key is the confirmation of intellectual property [8]. Knowledge collaboration in technology alliance is actually collaborative innovation behavior in the organization 
which has the advantageous resources in the strategic alliance, if the organization can't confirm the intellectual property rights effectively, whether underestimates or overestimates the value of intellectual property, will affect the effect and goal achievement of knowledge collaboration in technology alliance. If the value of intellectual property chosen by organization does not correspond to the effect of face value, so the cost and risk of technology alliance will be greatly increased, and may lead to rupture and internal friction for strategic cooperation. At the same time, the reliability and validity of intellectual property resources need all parties of organization participated in knowledge collaboration of technology alliance guarantee together, to ensure that the achievement of knowledge collaborative innovation in technology alliance is constructed on the basis of independent and complete intellectual property, and be able to bring the maximum benefit. Therefore, we need confirm and judge intellectual property in collaborative partner of technology alliance from aspects for authenticity, validity, reliability, integrity, progressiveness and utility. Only after a comprehensive and accurate confirmation, the development of knowledge collaborative technology alliance finally can be promoted. Of course, because of some situation such as the market reputation and trust of technology alliance, government intervention, selection of collaborative partners may be skipped in the knowledge collaboration process of technology alliance.

\section{Dynamic Upgrading Mechanism of Technology Alliance Based on Partner Selection}

In the promotion of knowledge collaboration partners, the technological innovation network has been continuously improved and upgraded in the alliance, the alliance technology innovation ability upgrade repeated, the speed of the upgrade is significantly higher than the state of nature. From the path and period of the development of technology alliance, the reasonable selection of knowledge collaboration partners can effectively improve the ability of collaborative innovation.

The development process of the special knowledge skill and the ability improvement of the knowledge collaboration partner are the key factors to improve the technology alliance ability in the initial stage. In general, the ability promotion of knowledge collaboration partners have the choice of a diversified direction, these capabilities must undergo the basic laws of the market will be able to effectively preserve. The limitation and decentralization of innovation resources determine the formation of starting point of the technological innovation ability of the two parties in the alliance. Once the technology alliance is formed, it will promote the industrial advantages of resources innovation and rapid integration, the strategic objectives of industrial technology innovation have gradually formed a clear plan, which makes the technology alliance ability can effectively improve . Meanwhile, the technology alliance is generally made up of the dominant innovation subject in the industry, through the promotion of industry breakthrough technology innovation action to promote the central intellectual property rights continue to appear. In addition, the government will conduct industrial innovation management using by the technology alliance, get innovation resources into the technology alliance through the major science and technology projects. This means to promote technology alliance to realize industrial key technologies and establishment and industrialization of technical standards, cooperative innovation ability will also accelerate the upgrade [8] during this period.

On the other hand, when the technology alliance has entered into the mature stage, the development speed of collaborative innovation ability is declining. The overall level is not too high and the short maturity make the collaborative innovation capability in alliance will face a huge risk, while the appropriate choice of knowledge collaboration partners can avoid the risk effectively. Firstly, the ability of a high level of knowledge collaboration partners enable the development of the alliance's innovation ability get a good promotion, so that the maturity of its peak can exist at a higher level. Secondly, landmark cooperation success in the technology alliance let other companies see the gap, then develop the innovation environment with "race each other" gradually in the stimulation of this gap, this environment will be the driving force of markable results expand to a wider field within the 
industry, all these can make the mature period of cooperative innovation alliance ability get better extension.

Finally, when the development of technology alliance to the late stage, collaborative innovation ability began to decline, the increase of risk not only affect by the lack of technical innovation in technology alliance, but also affect by emerging technology outside the alliance. In order to prevent such risks, the cooperation of the core enterprise in the technology alliance can contribute to the realization of the ability to jump, sustainable development and the turn the industry innovation ability continuing decline. Because of the core members in technology alliance are keys in industrial innovation system, their keen sense of ideas, making the external technological change of the alliance can be implemented, and the momentum of development of new technology in the future can be good grasp. The gather of innovation resources are advantages of technology alliance, these advantages can effectively conduct technical reform activities, let technology alliance capability accumulate and germinate at a higher level, to provide a better platform to promote the technology alliance continued.

\section{Conclusions}

For the collaborator commitments in technology alliance is mainly to the obligation and responsibility of the members in alliance, so as to play their own advantages to make up for the lack of other members in some aspects. Commitment provides a solid foundation for the innovation and development of technology alliance, and also plays a very important role in improving the overall efficiency of the technology alliance. Positive performance of commitment is the premise to the long-term stable common work between the members in the alliance, meanwhile affect each other's expectations and mutual trust relationship of knowledge collaboration partners for the alliance. Mutual support and effort between cooperation alliance members and technology development are inseparable, collaborator actively fulfill commitments and obligations in the collaboration alliance, to strengthen mutual trust between alliance enterprises, conducive to the mutual communication between the members in the organization, and to reduce the conflicts of cooperation.

\section{Acknowledgement}

This work was supported by the grants from Hubei Provincial Collaborative Innovation Centre of Agricultural E-Commerce (under Construction) (Wuhan Donghu university research [2016] No. 9 Document). This work was supported by the youth humanities and social science fund of Wuhan Donghu University (2016).

\section{References}

[1] During, John Reappraising the eclectic paradigm in an age H. of alliance Capitalism. Journal of International Business, Vol. 26(2010), p. 461-491

[2] HarbansL, Dhingra. Globalization of SMEs through strategic alliances.ASEAN Economic Bulletin, Vol.7 (2011), p. 47-65

[3] Peng S Chan and Dorothy Heide. Strategie Alliances in Technology: Key Competitive Weapon. SAM Advanced Management (2003)

[4] Chen H, Ma T. Technology adoption with limited foresight and uncertain technological learning. European Journal of Operational Research, Vol.239 (2014), p. 266-275

[5] Das T. K. and Teng, B. -S. A resource-based theory of strategic alliances]. Journal of Management, Vol.26 (2000), p. 31-61

[6] Hyung Sup Choi.Science policy mechanism and technology development strategy in the developing countries. Technological Forecasting \&Social Change, Vol.33 (2012), p. 279-292 
[7] Carayannis E G, Popescu D, Sipp C, Stewart M Technological learning for entrepreneurial development (TL4ED) in the knowledge economy (KE): Case studies and lessons learned. Technovation, Vol.26 (2011), p.419-443

[8] Damanpour F.Organizational Innovation: a Medi-analysis of Effects of Determinants and Moderators. Academy of Management Journal, Vol.34 (2010), p. 555-590 